\title{
Actively open-minded thinking and the political effects of its absence
}

\author{
Jonathan Baron* $^{*}$ Ozan Isler $^{\dagger} \quad$ Onurcan Yilmaz
}

\begin{abstract}
Actively Open-Minded Thinking (AOT) is a set of standards for rational thinking. Because the thinking of citizens and officials affects political decisions, good thinking is a moral virtue, like honesty. AOT standards have two functions: people try to follow their own standards; and they apply these standards to the evaluation of the thinking of others. The second function is especially important in public policy, where most of us often "outsource" our thinking to others. Individual differences in AOT primarily involve two dimensions: open-mindedness, avoiding "myside bias"; and overconfidence in a favored conclusion. The most dangerous political beliefs are those that are held with great confidence despite minimal or biased thinking. Here we review the recent literature on the role of AOT as a standard, and the correlations between AOT measures and particular political beliefs, such as acceptance of conspiracy theories. We argue for a "positive manifold" in which Enlightenment-based ideas about thinking and politics are all correlated with each other. We then report a study that tries to find the source of individual differences in this sort of "cognitive liberalism" and associated beliefs, comparing two major accounts: cultural background and thinking by oneself. We find evidence for both influences. But people often regard themselves as rebelling against their background, despite its actual influence on them.
\end{abstract}

Keywords: actively open-minded thinking, cognitive liberalism, myside bias, overconfidence

\section{Introduction: What is actively open-minded thinking?}

The term "actively open-minded thinking" (henceforth AOT) was introduced in the first (1988) edition Thinking and deciding (Baron, 2008) by the copy editor Christie Lerch, who

\footnotetext{
*Department of Psychology, University of Pennsylvania. Philadelphia. Email: jonathanbaron7@gmail.com.

${ }^{\dagger}$ BEST Centre, Queensland University of Technology. Brisbane, Australia.

${ }^{\ddagger}$ MINT Lab, Kadir Has University, Istanbul.
}

This article is a draft of an invited chapter for Divided: Open-Mindedness and Dogmatism in a Polarized World (Victor Ottati and Chadly Stern, editors), to be published by Oxford University Press. The final version will be shorter and otherwise revised. 
wanted a term for an idea running throughout the book. AOT now has a literature of its own, partly due to the extensive work of Keith Stanovich and his collaborators Maggie Toplak and Richard West. But the idea originated, nameless, in Baron (1985). Lerch's name tells the story. AOT is recommendation, a norm or standard, for how to think well, so that errors are avoided and goals are achieved. In this regard it resembles other concepts discussed in this book, although these are often stated as types of thinking to avoid, such as dogmatism. But the idea of distinguishing good and bad thinking is much the same.

This chapter begins with a discussion of how AOT differs from similar ideas. In particular, it arises from a general theory of optimal thinking, and proceeds from that to list two common departures from optimality: myside bias and overconfidence. Because AOT is a standard, it is endorsed (or opposed) to various degrees by ordinary people, and people generally try, with considerable success, to follow their own standards when they think. We can measure these standards with simple questionnaires, and it turns out that they predict a variety of politically relevant beliefs and practices. These concern not only our own thinking but also, importantly, whom we trust when we "outsource" our thinking to others, as we often do in political matters. We trust those who signal that they agree with our own standards of how to think. I review some of this (rapidly expanding) literature. We suggest here that individuals tend to differ systematically in their political and meta-cognitive beliefs, thus yielding a dimension of individual differences that we call "cognitive liberalism". Finally, we report a study concerned with the roles of cultural background and individual thought in causing cognitive liberalism. Although cognitive liberalism is correlated with cultural backgroud, people see the influence of background as largely opposing cognitive liberalism, and they attribute their own liberalism, insofar as it exists, to their own thought and the influences of others.

We assume that what appears to be increased political polarization in many nations is the result of irrational persistence of belief on one or both sides. Note that all it takes is one side. If the forces of un-reason are large enough to gain some political power, it is natural for the other side to resent them, to want their children not to marry them, and so on, but this does not mean that both sides are equally irrational. Extremism has existed on both sides of the political spectrum throughout the history of all democratic nations. Occasionally the extremists become powerful enough to control much of the government, thus increasing the conflict between the two sides, to the point where they become like warring tribes. That has happened recently in the U.S. at the national level and is still happening in the states. Thus, the problem of polarization in the U.S. (and in a few other countries such as Hungary and Brazil) is primarily a problem with the extremism of the political right, such as the takeover of the Republican party by radicals. Yes, the left harbors some irrational actors, but they are not in power anywhere except in sheltered domains like some universities. ${ }^{1}$ Irrational

${ }^{1}$ Their existence, however, provides some cover for politicians and scholars who want to say that both sides are equally at fault. That might have been true around 1968 in the U.S., when Baron, as an anti-war Democrat, argued with friends who thought that the U.S. was ready for a violent leftist revolution. But it is not true now. 
extremism of any sort is in part, perhaps in large part, due to the failure to think in a way that is actively open-minded.

\subsection{A formal approach to thinking}

Thinking is the effort to resolve doubt about what to do or what to believe. It necessarily involves some search, maybe only a little. We search our own minds for memories and newly constructed ideas, and we often search the external world over minutes or even years for a single episode of thought. We search for three different kinds of objects:

Possibilities are possible answers to the question that inspired thinking. These are "options" in the case of decisions or "propositions" in the case of thinking about beliefs. Each possibility has a "strength".

Evidence (arguments) consists of propositions that can affect the strength of different possibilities.

Goals (criteria, objectives, values) affect how the evidence affects the strength of each possibility.

If the single goal is to get a drink of water, evidence that the drinking fountain is out of order will weaken that possible option. Sometimes the only goal is to determine what is true, but decisions usually involve more than one goal, hence possible conflict. Goals can be matters of degree, like the goal of making money.

Inference is the process of using the evidence and goals. It can be simple and automatic, but it can also involve the use of various principles, such as the rules of logic. This general outline is called the "search-inference framework".

These processes of search and inference are not ordered. In an extended episode of thinking they operate in cycles. A possibility may emerge. The search for goals may yield a goal that it subverts. This may lead to a search for a second possibility. Goals may elicit search for other goals, as when we ask "What is the real purpose of what we are trying to do here." We can, however think of all these processes as filling in a table like the following, where the rows are possibilities, the columns are goals, and the cells are arguments, each of which may fall into several cells. And each cell has a value, positive or negative, for the effect of that evidence on a given possibility achieving a given goal. Each goal may have a strength as well, so the strength of the possibilities may be computed from this table by weighing the cell entries by the column weights and then adding up the cells in each row (after this adjustment). But nobody needs to do the math; it is just a way of making the search-inference framework concrete conceptually.

\begin{tabular}{|c|c|c|c|}
\hline Option & G1 & \multicolumn{2}{|c|}{ G2 $\longleftarrow$ G3 } \\
\hline \hline P1 & e1+ & e2- & \\
\hline P2 & & e3+ & \\
\hline P3 & e4+ & & e5+ \\
\hline
\end{tabular}


This process is governed by the setting of two parameters: direction and confidence. The direction of search and inference may favor or oppose the current strongest possibility. The optimal setting of this parameter is neutrality, so that it is fair to the current possibility and the alternatives. The most common departure from optimality is "myside bias" (Perkins, 2020), that is, search and inference that favors the strongest possibility and thus tends to close off thinking prematurely by neglecting alternatives. (If people always favored the alternative, they could cycle forever and rarely reach a conclusion; they would probably notice that they do this and change the way they think, although a few "obsessive" people may not.) Note that myside bias is unlikely to lead to correction of erroneous conclusions. But "neutrality" does not imply neglect of evidence previously obtained: I need not throw away everything I know about Hitler in the face of new evidence that he was once kind to a Jew.

Confidence in the currently favored possibility is a function of the strengths of the possibilities under consideration. It is high when the favored possibility is strong and the next best alternative is weak. Thinking should continue to the extent to which confidence is low and the expected benefit of further thinking by oneself, another form of confidence, is high. ${ }^{2}$ Thinking often has a cost, at least in time that could be spent on other things, and when the cost exceeds the expected benefit, thinking should stop. In this regard, the theory of optimal thinking differs from theories that simply assume that more thinking is better. In the case of politics, the expected benefit of further thinking on ones own may be lower than then the benefit of outsourcing to trusted others. Although I have some understanding of macroeconomics, I know that others I can easily consult have a much better understanding than I do. In politics, people may think too much on their own and reach erroneous conclusions (just as they may trust the wrong sources).

The most common error is overconfidence in the favored possibility, that is, high confidence that is not warranted by the thinking done so far. This is exacerbated by myside bias, which can lead directly to such unwarranted high confidence in the favored possibility by failing to uncover evidence against it (or for an alternative). Thus overconfidence and myside bias tend to correlate, but they are not the same.

When we evaluate the thinking and conclusions of others, in view of the importance of confidence being warranted, we can be tolerant of their expressions of uncertainty. Indeed, a source's expressions of uncertainty indicate that the same source's expressions of certainty are warranted and that the sources is more trustworthy than one who never seems uncertain. AOT must thus be defined in terms of two virtues: fairness to possibilities; and willingness to accept low confidence and uncertainty when that is warranted. Warranted low confidence implies openness to further thought, which need not be done immediately.

\footnotetext{
${ }^{2}$ Confidence in the thinking done so far and confidence in future thinking have opposite effects on whether thinking continues (Baron, 1985). The literature on optimal stopping suggests that errors occur in both directions (e.g., Baron et al., 1991; Lee \& Courey, 2021 - which contains other recent citations). This parameter deserves further study, especially for modeling of individual behavior.
} 


\subsection{Individual differences in cognitive style}

AOT provides a somewhat different account of individual differences in cognitive style from what seem to be the two other major current approaches: dual-process theory, and the idea of "reflection".

\subsubsection{Dual-process theory and cognitive reflection}

A long tradition in psychology has distinguished between responses that are automatic, requiring very little effort and thus may occur even when they are incorrect, and responses that require effort (Brian \& Harter, 1899; Stroop, 1935; Shiffrin \& Schneider, 1977; Evans \& Stanovich, 2013 [for a more recent review]; Schneider \& Shiffrin, 1977; Kahneman, 2011). A recent version of this idea is corrective dual-process theory, which holds that, in many tasks, the automatic response (System 1) occurs and is then sometimes recognized as suspect, so that a second step is to re-visit the problem using System 2, which is reflective and requires some effort. A simple way to assess this effect is the two-response method (Bago \& De Neys, 2017), in which the subject is instructed to provide an immediate intuitive response followed by a final response.

Corrective dual-process theory has been usefully applied to several areas, including memory tasks, logic, and trick problems (e.g., Thompson et al., 2011; Ackerman \& Thompson, 2017). Importantly, the switch from System 1 to System 2 does not always occur and depends on the strength of confidence in the System 1 output (also called "feeling of rightness" in the literature), as well as individual differences (e.g., Galotti et al., 1986). An example of a commonly used trick problem is part of the original Cognitive Reflection Test (CRT; Frederick, 2005): "If it takes 5 machines 5 minutes to make 5 widgets, how long would it take 100 machines to make 100 widgets?" System 1 would produce an answer of 100 minutes, by simple analogy. Many people give that answer. Others may worry that something might be wrong with it (or they never think of it), and they proceed to solve the problem more systematically (perhaps by imagining 20 groups of 5 machines working all at once).

Performance on the CRT correlates with a large variety of other tasks and judgments, including some that involve politics. In general CRT correlates negatively with social conservatism and with measures associated with it (e.g., Pennycook et al., 2020; Ross et al., 2021; Fuhrer \& Cova, 2020) but not with economic conservatism, when these two types of beliefs are distinguished (e.g., Deppe et al., 2015; Yilmaz \& Saribay, 2017). ${ }^{3}$

Ackerman and Thompson (2017) present a version of dual-system theory that is much like the search-inference framework described above. In particular, like the search-inference framework, it allows cycling, in which an extended thougth process can take many steps, each of which leads to a representation of confidence (or feeling of rightness), which then

\footnotetext{
${ }^{3}$ Yilmaz and Saribay found a small negative correlation with a verbal version of the CRT, but data from Deppe et al., show a small positive correlation.
} 
affects whether further thinking occurs. It does not (and is not meant to) specify optimal parameters, as the general model behind AOT does.

\subsubsection{Reflection/impulsivity (R/I)}

Baron et al. (2015) suggested that the predictive power of the CRT arose largely because it measures a different dimension of cognitive style, namely, reflection/impulsivity (R/I).

This idea arose initially in the study of children, who could be assessed as reflective or impulsive on the basis of their performance in problem-solving tasks that did not require particular knowledge (Kagan et al., 1964). These tasks, like most cognitive tasks, show a speed-accuracy trade-off. People (including children) can solve problems quickly (impulsively), at the expense of lower accuracy, or the could (reflectively) take more time to avoid errors. A useful and general measure of $\mathrm{R} / \mathrm{I}$ is the $\mathrm{z}$ score of accuracy plus the $\mathrm{z}$ score of ( $\log$ ) response time (Baron et al., 1986). ${ }^{4} \mathrm{R} / \mathrm{I}$ correlates with a great variety of measures of success, not just in problem solving but also in school work and self-control (Messer, 1976; Baron et al., 1986).

The CRT is usually scored in terms of the proportion of correctly answered items in a short test. But it turns out that mean log response time does just as well, at least for predicting some measures (Baron et al., 2015). Getting correct answer (regardless of the presence of seductive lures as intuitive responses) requires more time. Other measures can also be scored as measures of R/I such as the belief-bias task, which ask subjects to judge the validity of syllogisms, when the conclusion of the syllogism serves as a lure, e.g., "All flowers have petals. Roses have petals. If these two statements are true, can we conclude from them that roses are flowers?" (Baron et al., 2015).

Note that the R/I dimension implicitly assumes that more thought is always better. By contrast, AOT implies that some amount of thought is optimal for each situation. The fact that R/I predicts so many measures of good performance suggests that most people, in the tasks that yield these measures, are thinking less than the optimum. But R/I differs from AOT in other ways. For example, myside bias can occur even in extensive thinking, as when thinking is used to justify an incorrect conclusion (Wason \& Evans, 1975). ${ }^{5}$

In sum, AOT is about Aristotelian virtues. That is, there is an optimal value on each relevant dimension, with declines in performance from the optimum on both sides. We call

4Interestingly, this measure is almost by definition orthogonal to "ability" at the task, which would be higher when speed is higher, hence "minus" instead of "plus". Yet many tasks show a positive correlation between response time and accuracy, suggesting that variation in R/I is greater than variation in ability in those tasks.

${ }^{5} \mathrm{R} / \mathrm{I}$ is closely related to a more recent approach to individual differences in thinking, the use of driftdiffusion models (Ratcliff et al., 2015). These models describe performance (on a variety of tasks, including those that involve thinking) as a random walk, starting somewhere between two boundaries, each indicating one of two possible responses, and taking random steps toward or away from the 'correct boundary. If the boundaries are farther apart, the process takes more time but is less likely to hit the wrong boundary as a result of random steps. Thus a single parameter can represent the speed/accuracy trade-off, but individuals may also differ in other parameters, such as the starting point (bias toward one side or the other). 
movement in one direction a virtue because most often actual behavior falls on the other side of the optimum. For example, "courage" is a virtue because most people are too timid in situations that require risk taking. In AOT, more time is not always better, especially when outside trustworthy sources are available. R/I implicitly assumes that more time is always better.

\subsubsection{Measures of AOT}

System 2 and R/I can be assessed through performance on test items, those with correct and incorrect answers, and other tasks. Several measures like this are sensitive to myside bias and overconfidence. But measures like these are also affected by other factors aside from cognitive style. For example, the CRT is affected by knowledge specific to mathematics.

Here are some examples of performance measures of myside bias:

- In a direct measure of myside bias, Perkins (2000, based on a 1986 report) asked students simply to write down arguments about "vexed" issues, such as "Would a nuclear freeze agreement signed between the U.S and the U.S.S.R. significantly reduce the possibility of world war?" Students listed more myside arguments than otherside arguments, but when they were asked to write more arguments on both sides they wrote more additional otherside arguments, thus showing that they could have written them initially but did not. Baron (1995) used a similar task to assess individual differences, and found that myside bias in the task was correlated with myside bias in judgments of the quality of other people's lists.

- In predecisional distortion, the experimenter creates a bias toward one option in a choice task (e.g., by presenting positive evidence for that option first), which then makes the subject more likely to choose that item because the subject gives more weight to evidence favoring that option over others, even if the others would be chosen more often if the information were presented in a random order (e.g., Russo et al., 2006; see Brownstein, 2003, for a review).

- In belief overkill (Jervis, 1976), people distort arguments so that all arguments favor a preferred option, even though it would be perfectly reasonable to acknowledge that the option should be chosen despite some negatives because these were outweighed by the positives. Baron (2009) found striking individual differences in this effect, with some subjects showing no apparent bias at all.

- Probability distortion is, like belief overkill, a distortion of one of the arguments concerning an action with some risk, in which the judged probability of favorable outcomes increases and the probability of unfavorable outcomes decreases (DeKay et al., 2009).

- Polarization occurs when the presentation of evidence (argument) that are on the whole neutral, because they conflict in which side they favor, increases the judged 
strength of the side initially favored. Although some effects of this sort (such as that of Lord et al., 1979) can be explained in terms of rational use of prior beliefs in sources of evidence (Jern et al., 2014), other evidence for polarization is more difficult to explain this way because all the evidence comes from the same source (e.g., Meszaros et al., 1996).

- Selective exposure is biased search for external information that is known in advance to support favored possibilities. Female coffee drinkers don't want to read articles about how coffee causes breast cancer. This effect varies in magnitude (Hart et al., 2009) and is sometimes difficult to demonstrate because people sometimes seek out otherside arguments in order to rebut them, especially if they think that the arguments will be easy to rebut.

But AOT is most often assessed through self-report tests concerning norms for what good thinking is. As noted, people generally try to follow their own standards, so these correlate with performance measures. Here some items in current use (not in original order; “(-)" indicates reverse scoring):

\section{- Myside bias items (reverse scoring indicated):}

- People should take into consideration evidence that goes against conclusions they favor.

- People should revise their conclusions in response to relevant new information.

- Changing your mind is a sign of weakness. (-)

- People should search actively for reasons why they might be wrong.

- It is OK to ignore evidence against your established beliefs. (-)

- It is important to be loyal to your beliefs even when evidence is brought to bear against them. (-)

- When faced with a puzzling question, we should try to consider more than one possible answer before reaching a conclusion.

\section{- Overconfidence items:}

- True experts are willing to admit to themselves and others that they are uncertain or that they don't know the answer.

- Being undecided or unsure is the result of muddled thinking. (-)

- There is nothing wrong with being undecided about many issues.

- It is best to be confident in a conclusion even when we have good reasons to question it. (-) 
A scale consisting of these items (in a different order) had a reliability coefficient $(\alpha)$ of .86 , with no apparent separation of the two item groups, in a sample of adults used in the study we report below. But many findings suggest that a variety of scales of this sort, with somewhat different sets of items, are equally reliable and equally useful at predicting other measures.

Scales like this one are correlated with a variety of measures of cognitive biases, such as base-rate neglect, gambler's fallacy, conjunction effect, denominator neglect, Wason's 4-card task, and outcome bias. Toplak et al. (2014) present some of these results and cite earlier papers by members of this team (especially Stanovich and West). Haran et al. (2013) describe still other results of this sort.

\subsubsection{AOT beliefs and thinking: AOT as metacognition}

We can view AOT as a form of metacognition, that is, thinking about thinking. People evaluate their own thinking and the thinking of others according to certain standards, and they try to use these standards to control the way they think themselves. For example, Baron (1991) found correlations between grades given to other students' hypothetical thinking as a function of whether it was 1- or 2-sided, and their own used of two-sided thinking in discussing a novel problem (allocation of ocean mineral resources). Similarly, Baron (1995, as noted earlier) found correlations between myside bias in thinking about abortion and judgment of other people's thinking about the same issue.

AOT beliefs, as measured with short scale like the items just described, correlates with myside bias in the evaluation of others' thinking (Baron, 2019). It also correlates with overconfidence: in the online data from Sinclair et al. (2020), AOT correlates positively

with accuracy in distinguishing false "urban myths" from true trivia statements $(r=.37$, and .27 in the two samples, respectively) but negatively with confidence in those judgments $(-.27,-.18)$.

In sum, AOT is primarily a metacognitive trait of holding and applying standards for thinking, standards consistent with an account of optimal thinking. By contrast, R/I and corrective dual-system models are task-independent (hence generally applicable) measures of thinking itself.

Historically, the standards of AOT may have arisen from people reflecting on what they are doing. Other forms of metacognition arise early in childhood (Flavell, 1979).

\section{Political correlates of AOT: cognitive liberalism and its enemies}

AOT measures correlate not only with cognitive tasks but also with various measures of political attitudes, and various other scales that have been used to assess the relation between cognitive style and political attitudes. We might even think that there is a general trait of 
"cognitive liberalism", which encompasses cognitive style and political liberalism of a certain sort. We could think of this as somewhat analogous to the $\mathrm{g}$ factor in intelligence. All the components correlate with each other to some degree, as if there were some single underlying trait affecting everything. Such a trait may not exist, yet question of what accounts for these correlations is worth pursuing, as we discuss later. Specifically, the following correlations of AOT have been observed.

- Cosmopolitanism, in the sense of caring about the world, and opposing parochialism and nationalism, e.g., favoring immigration.

- Opposing social conservatism, that is, political views based on tradition that has been handed down for generations.

- Opposition to authoritarian religion, especially Divine Command Theory, the belief that we must accept the commands of God, because we are incapable of reasoning ourselves.

- Utilitarian moral reasoning (based on consequences for all affected), as opposed to deontology (morality based on rules, rights and duties).

- Acceptance of actively open-minded thinking as a standard.

- Trust in (good) science.

Data for the British Election Survey (wave 8, 2016; Fieldhose et al., 2018), which included a version of the AOT scale, illustrate the connection with cosmopolitanism. To begin, some items seemed to capture parochialism (the opposite of cosmopolitanism) and we put them into a scale:

- The UK should help other EU members in times of crisis

- Should EU citizens be able to claim child-benefit for children not in the UK

- Good or bad for Britain: Allowing the free movement of workers within Europe

- Allow more asylum seekers to come to UK

- Britain should allow more workers from other EU countries

- Britain should allow more workers from outside the EU

- Allow more student to come to UK

- Allow more families of people who already live here to come to UK

- Self: Allow more or fewer immigrants

- EU Referendum vote intention

Figure 1 shows the correlations from the raw data. Of primary interest are those with AOT and Brexit, but the other correlations generally support the idea of a general dimension of cognitive liberalism. Correlations with age and education suggest that younger and more 


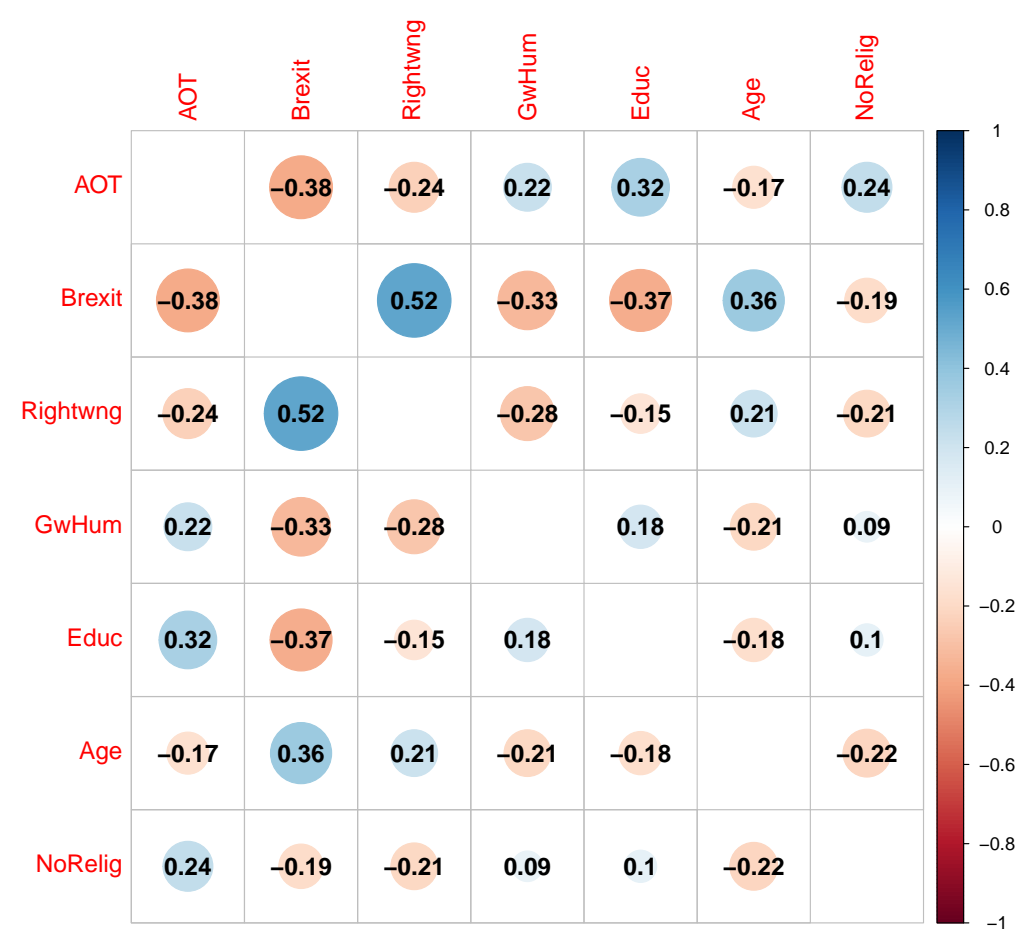

FIGURE 1: Correlations from British Election Survey: Rightwing is a measure of right wing political attitudes; GwHum is belief that global warming is largely cause by humans.

educated people are higher on this dimension. Although the correlations in Figure 1 are not astoundingly high, they do suggest that something like cognitive liberalism is at work.

Another informative set of correlations comes from a study of susceptibility to fake news (Bronstein, 2018). Subjects saw 12 fake and 12 real headlines with pictures and rated "the accuracy of each headline based on the degree to which they believed the headline described something that actually happened." Examples of fake headlines were: "Mike Pence: Gay Conversion Therapy Saved My Marriage. Vice President-elect claims that a 1983 conversion therapy saved him.”; "Donald Trump Protester Speaks Out: 'I Was Paid \$3,500 To Protest Trump's Rally.' PHOENIX, AZ (AP) — For months now, rumors have circulated the internet that individuals were being paid to protest at rallies held by presidential hopeful Donald Trump. ..." Figure 2 shows the major correlational results. It is clear that AOT is correlated with susceptibility to delusions, dogmatism, and religious fundamentalism. It also correlates negatively with judged accuracy of fake news but positively with judged accuracy of real news; the combination indicates that AOT is correlated with discrimination of fake from real. The CRT shows similar correlations, but they are much smaller. Sinclair et al. (2020) found other relevant correlations, particularly with right-wing authoritarianism.

Others have observed positive correlations of AOT with utilitarian responding, and a scale measuring support for utilitarian beliefs (Baron et al., 2015), and negative correlations with superstitious belief (Svedholm-Häkkinen \& Lindeman, 2017); supernatural religious belief (Pennycook et al., 2014), and belief in divine-command theory (Baron et al., 2015), 


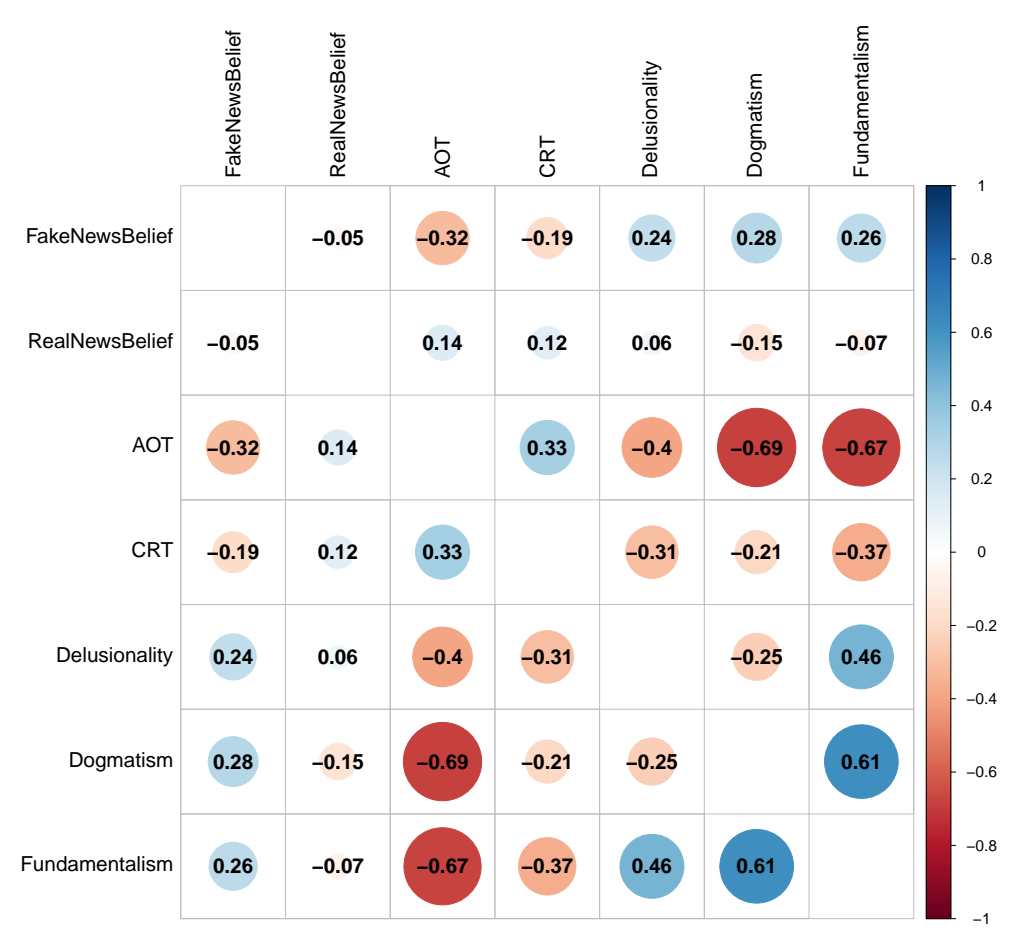

Figure 2: Correlations from Bronstein et al.,2019. The last three measures are based on standard scales.

the belief that humans are incapable of understanding the moral commandments from God and thus should not question them (Piazza \& Landy, 2013). Sirota \& Juanchich (2018, public data) found $\mathrm{r}=.43$ for AOT correlation with paranormal belief (but .27 for CRT). Note that these sorts of religious and supernatural beliefs are the sources of political disputes, where the more conservative religious beliefs tend to be associated with right-wing politics, especially "social conservatism" as distinct from economic conservatism. Baron (2017) also noticed a correlation of -.27 between AOT and a measure of "political conservatism" in a study in which conservatism did not correlate at all with CRT score.

Importantly, AOT standards also correlate with measures of trust in sources, when the sources signal whether or not they follow those standards (Baron, 2019; Baron \& High, 2019). For example, Baron and High asked subjects how much they would trust the judgment of the person who made each of two types of statements. In one study, the statements differed in indications of myside bias, e.g.:

- Type1 It would be flat out irresponsible to oppose tuition-free access to community or technical college programs - it will create a wave of new workers prepared for the 21 st century economy.

- Type2 Tuition-free access to community or technical college programs will create a wave of new workers prepared for the 21 st century economy. Yes, it is expensive, but it is worth the price. 
In a second study, they differed in indications of overconfidence, e.g.:

- "Those tremors don't mean anything. An earthquake won’t happen. (scientist)"

- "Those tremors probably don't mean anything. An earthquake is unlikely. (scientist)"

For both types of items, the difference in ratings of the two sources correlated with the score on an AOT scale. Thus, people who themselves oppose AOT standards are more likely to trust those who indicated absence of those standards.

\section{Where does cognitive liberalism come from?}

What can account for the correlations just described? In particular, AOT standards correlate both with actual cognitive processes and with measures of politically relevant beliefs.

One explanation that we can largely dismiss is that the correlations result from differences in the thinking that subjects do in psychology experiments themselves. For example, correlations of the CRT with various tasks could results from reflection/impulsivity as manifest in the tasks themselves. This sort of effect might explain some correlations: impulsive processing of news headlines might lead to more judgments that they are real; and impulsive responses to moral dilemmas might favor simple deontological principles. But it is clear that such within-experiment effects cannot explain the whole pattern of results. The major individual differences seem likely to result from differences in what subjects bring to experiments. For example, subjects who make more deontological responses have probably accepted deontological approaches in their real-world judgments outside of the laboratory. Two other explanations seem more plausible.

Cultural diversity. Pre-Enlightenment and post-Enlightenment cultures may exist in the same population. Older, traditional beliefs and values associated with (but not limited to) religion vs. modern liberalism (tolerance, respect for science, etc.) may thrive in some regions, usually rural ones with limited opportunities for higher education. Residents of cities, by contrast, tend to have more education, and more exposure to people speaking different languages and from different regions. Respect for their fellow citizens may spill over into greater willingness to consider the "other side" even when the other side does not come from other people.

In sum, cognitive liberalism is an attribute of cultural groups. Most studies of individual differences do not restrict themselves to one cultural group, which would be difficult given the fact that membership in most cultural group is a matter of degree. The sample is usually national, and it need not be nationally representative in order to include considerable cultural variation. Cultural variation itself could arise from environmental effects (such as isolation) on individual development. Once it exists, it could be maintained by mechanism that create cultural stability across generations (Cavalli-Sforza et al., 1982). Further investigation of cultural history, including both written history and language itself, may be useful. 
Development of thinking standards. People are surely influenced by the cultural background they come from, but many people depart from it. Without such departures, it is hard to see how cultural change could happen. And it has happened extensively throughout history. The cultures that produced Socrates, Confucius, and many other ancient sages seem unlikely to have existed before the development of writing (even when what we know of the early sages comes mostly from the writings of their students), although we cannot know for sure. The enlightenment that took place in Europe, and, more generally, the Renaissance surely involved cultural change. Hallpike (2004) provides an account of the cultural evolution of morality, and how it was influenced by such economic factors as the development of cities.

Thus, another determinant of thinking standards may be people's own development over their lives, perhaps especially in adolescence. Much evidence for this sort of development occurs in the literature in developmental psychology (Kohlberg, 1969; Kuhn, 1989; Marcia, 1980; Perry, 1971). Education seems to play a major role, although it difficult to separate education itself from the cultural differences that cause people to get more or less of it. Whatever the cause, development of thinking continues at least into early adulthood, in ways that would seem to increase AOT in some people. For example, in Kohlberg's identified transition from "conventional" to "post-conventional" moral reasoning, the former is the identification of morality with what is socially prescribed, such as law or convention, while the latter allows criticism of conventional morality from a more general perspective, such as the sort of moral theory that philosophers discuss.

AOT standards themselves could arise from reflection on conflict of alternative views, which would be more likely in contexts of cultural diversity. People with different beliefs may start asking questions such as "How do I know that my beliefs are more correct than hers? Where do accurate beliefs come from?" Such questions could result in the idea that beliefs are more likely to be correct if they have withstood challenges. AOT standards could also arise from institutional efforts to reduce cultural conflict. Schools in the U.S. teach their students to respect others and listen to them, and it is in these terms that students themselves describe their open-mindedness (Metz et al., 2020).

\section{Cultural and individual determinants: Preliminary stud- ies}

Ideally we could test the roles of cultural transmission and individual development with about 10 years of longitudinal data. Lacking both time and money, we asked 232 people from a panel Baron has used for other studies to engage retrospect on their own development. ${ }^{6}$

We presented five short scales measuring different aspects of cognitive liberalism. The utilitarianism (abbreviates as Uscale in figures) scale was home-made, focusing on two

${ }^{6}$ Two other subjects were omitted for nonsense responses. 
features of utilitarianism that distinguish it (and other consequentialist views) from other moral systems: making decisions according to consequences rather than rules; and favoring harmful actions when they prevent greater harm. Three items from Piazza and Landy (2013) measured belief in Divine Comman Theory (DivineCT or DCT). Three other home-made items assessed religion (Relig) two concerned with belief in God but one just asking about religiosity. Six home-made items assessing general political views (Liberal); four defined conservatism as adherence to traditional views and reluctance to move away from them, a feature that could apply to most cultures around the world regardless of current defining issues, and the remaining two items simply asked about "right" vs. "left". Nine items assessed AOT. For each of the 27 items, we asked subjects their current views, the views they started with, and the views of their family background. We could thus assess changes over time, as seen by each subject.

\subsection{Method}

The introduction to "Time travel" (the name we used for all these studies) read:

This is a study of how people's attitudes change over their lives. Unfortunately, we do not yet have a time-travel machine that will take you back to the time when you were 12 years old. So we are asking you to do your best to reflect on how you came to hold your current attitudes on a number of abstract issues.

There are various influences that can cause people to change their views. Sometimes they have an effect and sometimes they do not. But we want to know about each influence that occurred and could have affected your views, whether it had an effect or not. For example, someone may have tried to persuade you of a different view, and failed. Or you may have considered a different view, on your own, but ultimately decided that your original view was best.

The main part of the study presented 28 items, making up 5 scales. Each question was answered on a 1-5 scale labeled "Completely disagree" at one end and "Completely agree" at the other. The scales were as follows:

\section{Uscale (utilitarianism).}

- When a moral rule leads to outcomes that are worse than those from breaking the rule, we should follow the rule. (R)

- When a moral rule leads to outcomes that are worse than those from breaking the rule, we should break the rule.

- When two options harm other people in the same ways, we should choose the option that harms fewer people.

- When some action causes harm to some people but prevents the same harm to many more people, we should act. 
- It is morally wrong to harm some people in order to prevent the same harm to more people. (R)

- Sometimes we should follow moral rules that prevent us from doing what is best on the whole. (R)

\section{DivineCT. (divine command and religion items)}

- The truth about morality is revealed only by God.

- Acts that are immoral are immoral because God forbids them.

- We don't need to try to figure out what is right and wrong, the answers have already been given to us by God.

\section{Relig.}

- There is a god that truly exists.

- God, and gods, do not exist, despite what people believe.

- I consider myself a religious person.

\section{Liberal (political liberalism).}

- I am reluctant to make any large-scale changes to the social order. (R)

- I favor stability in society, even if there seem to be problems with the current system. (R)

- Society should be quicker to throw out old ideas and traditions and to adopt new thinking and customs.

- Traditional values, customs, and morality have a lot wrong with them.

- On SOCIAL matters, my political orientation is on the right (conservative) as opposed to left. (Here, 'agree' means that you are right wing, and 'disagree' means that you are left wing.) (R)

- On ECONOMIC matters, my political orientation is on the right (conservative) as opposed to left. (R)

\section{AOT.}

- Willingness to be convinced by opposing arguments is a sign of good character.

- People should take into consideration evidence that goes against conclusions they favor.

- Being undecided or unsure is the result of muddled thinking. (-)

- People should revise their conclusions in response to relevant new information.

- Changing your mind is a sign of weakness. (-)

- People should search actively for reasons why they might be wrong. 
- It is OK to ignore evidence against your established beliefs. (-)

- It is important to be loyal to your beliefs even when evidence is brought to bear against them. (-)

- There is nothing wrong with being undecided about many issues.

- When faced with a puzzling question, we should try to consider more than one possible answer before reaching a conclusion.

After each items, we asked the following questions:

Past. How would you have answered this question earlier in your life, when you first might have been able to understand the question as you do now?

Upbring. How would those who brought you up have wanted you to answer this question?

Please indicate how each the following influenced your views. ${ }^{7}$

I thought about things like this myself.

[Strongly toward 'disagree' ... Strongly toward 'agree']

People involved in my upbringing.

Other people I met later.

My formal education (e.g., school, college).

Specific life experiences that I had.

\subsection{Results}

Figure 3 shows the correlations of the scales used, with the reliabilities $(\alpha)$ in the diagonals. Above the diagonal the correlations are corrected for attenuation (by unreliability). The utiliarianism scale had low reliability, but we retain it because it included two different components, which do not necessarily arise together (consequences vs. rules, and acceptance of harm to some for the greater good). The main result here is that everything correlates with everything else, to some extent, as noted in the literature just reviewed. This is called a positive manifold.

Figure 4 shows the means, positive means indicate more cognitively liberal responses. Our sample was not particularly liberal politically, and they tended to be religious, although, on the average, did not accept Divine Command Theory.

Figure 5 shows the difference between current and Past ("earlier in your life, when you first might have been able to understand the question ..."). In retrospect, on average,

\footnotetext{
130.

${ }^{7}$ Thesse questions were added after 102 subjects had answered all the other questions without them, leaving
} 


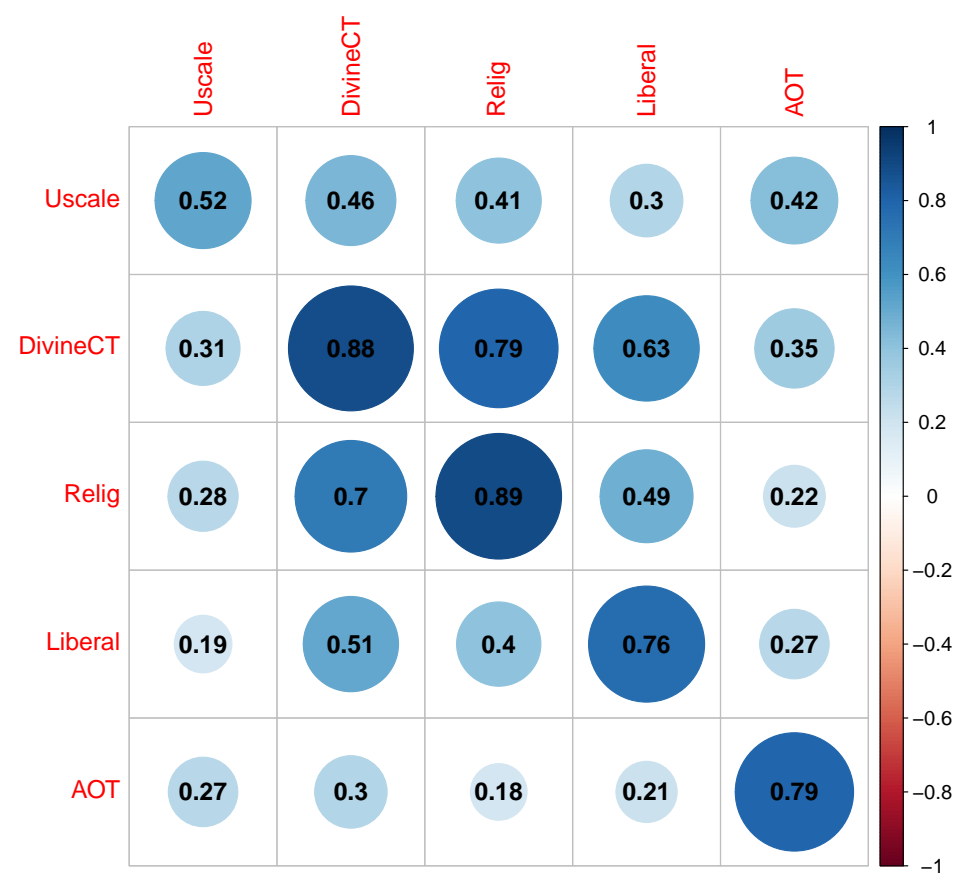

FIGURE 3: Main correlations of scales are all positive. Diagonal entries are reliability estimates (g6); correlations above the diagonal are corrected for unreliability (disattenuated).

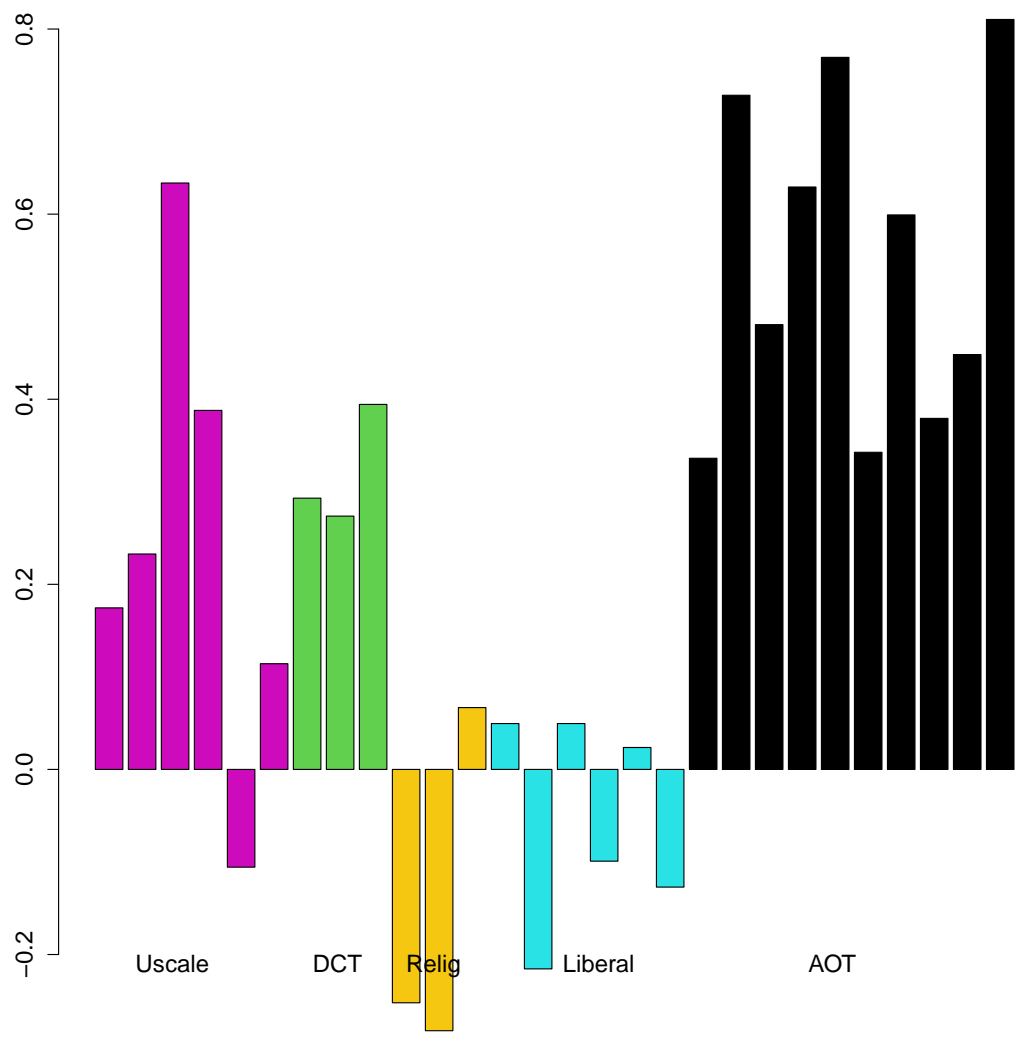

Figure 4: Means in the direction of liberalism on a scale from -1 to 1. 
people thought that they become more cognitively liberal in every domain except politics ("Liberal").

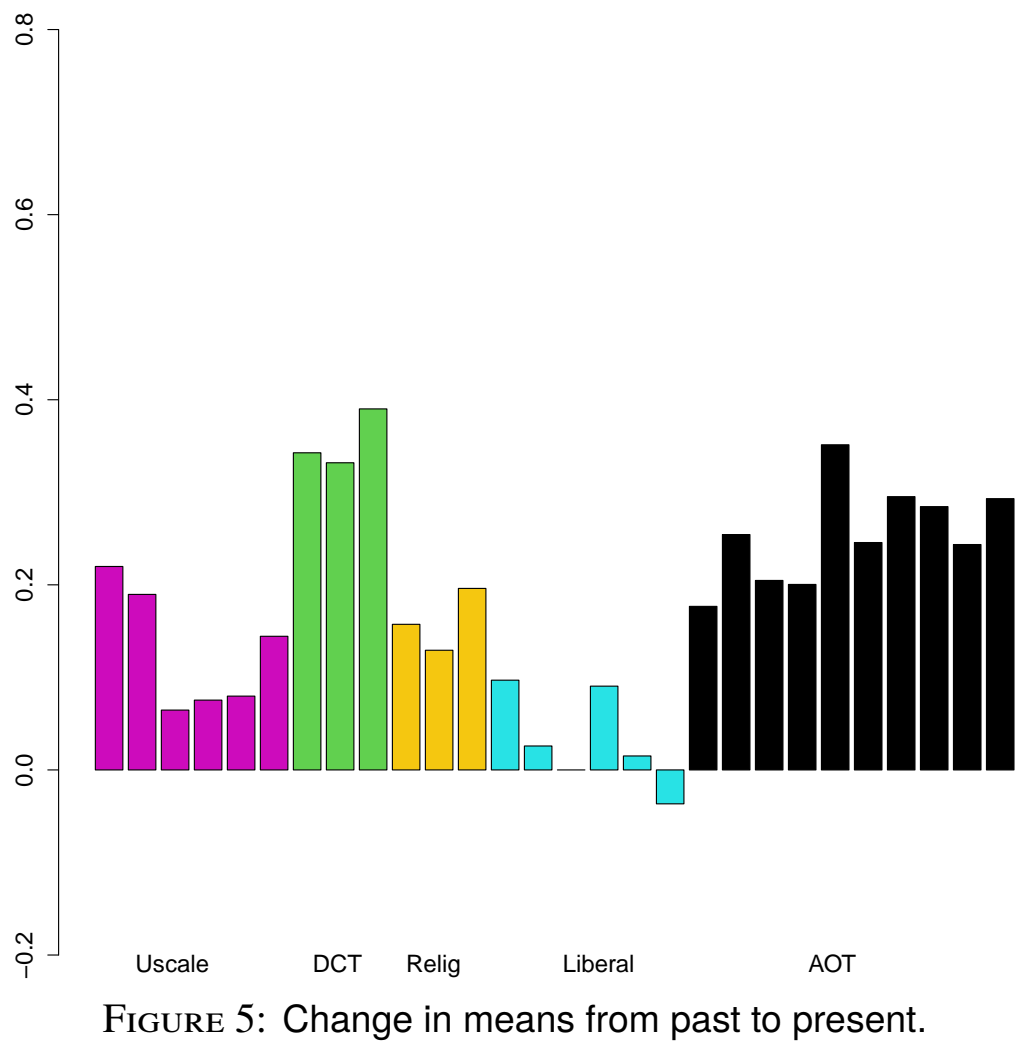

Figure 6 shows the difference between past and Upbring ("How would those who brought you up have wanted you to answer this question?"). Apparently people saw themselves as more liberal politically than their background, even when they were young.

A major question is whether upbringing affects current beliefs. Figure 7 shows, for each of the 28 items, the correlation between Upbring and current answers. It is clear that upbringing (as remembered) plays a substantial role.

Figure 8 shows that most of this influence is specific to the scale involved. Off the diagonal, the correlations are mostly non-existent.

As noted above, we also asked questions about the direction of influence received from five sources: Thought (own thinking), Upbring, Others, Educ (eduation), and Exper (Experience). (As noted these questions were asked only of the last 130 subjects.) These questions were not mutually exclusive, so we could examine their correlations with each other. For subject means of each measure, Thought, Others, Educ, and Exper correlated highly with each other, and Upbring did not correlate at all with items in this group. Based on the alpha() function of the psych package of R (Revelle, 2021), the correlation of Upbring with the mean of the other four was -.043 . The four other "items" had a reliability $(\alpha)$ coefficient of .86 , which is quite high for a four-item test. This high correlation makes sense if we think that people's own thinking is inspired by inputs from others and from 


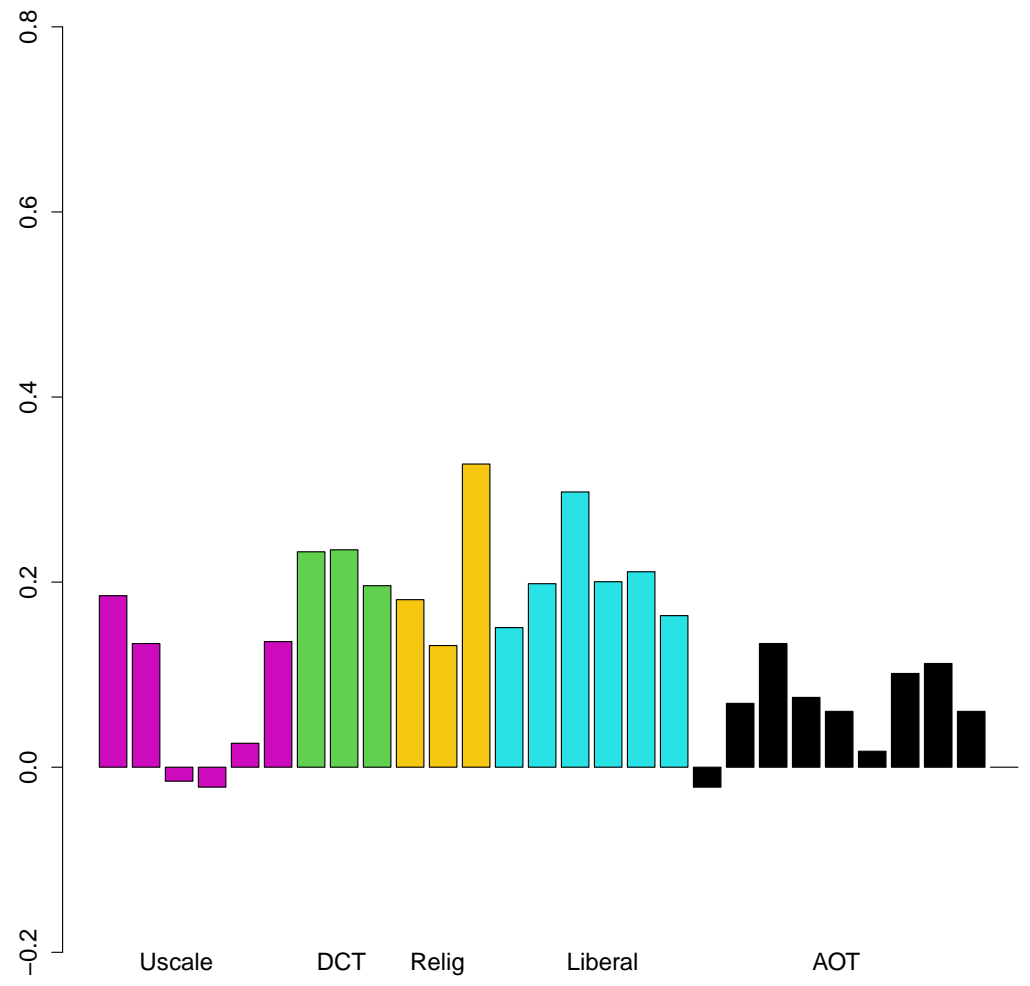

Figure 6: Comparison of past to upbringing.

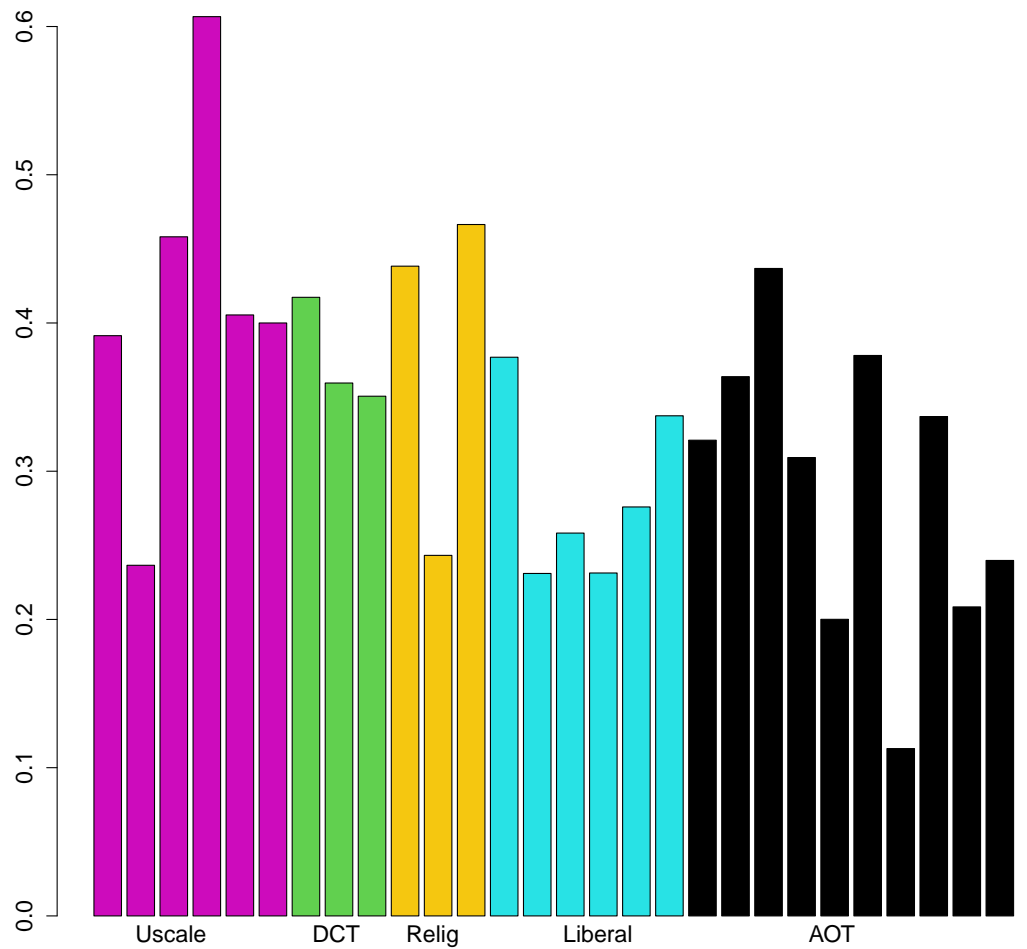

FIGURE 7: Correlations by item of upbringing with current answers. 


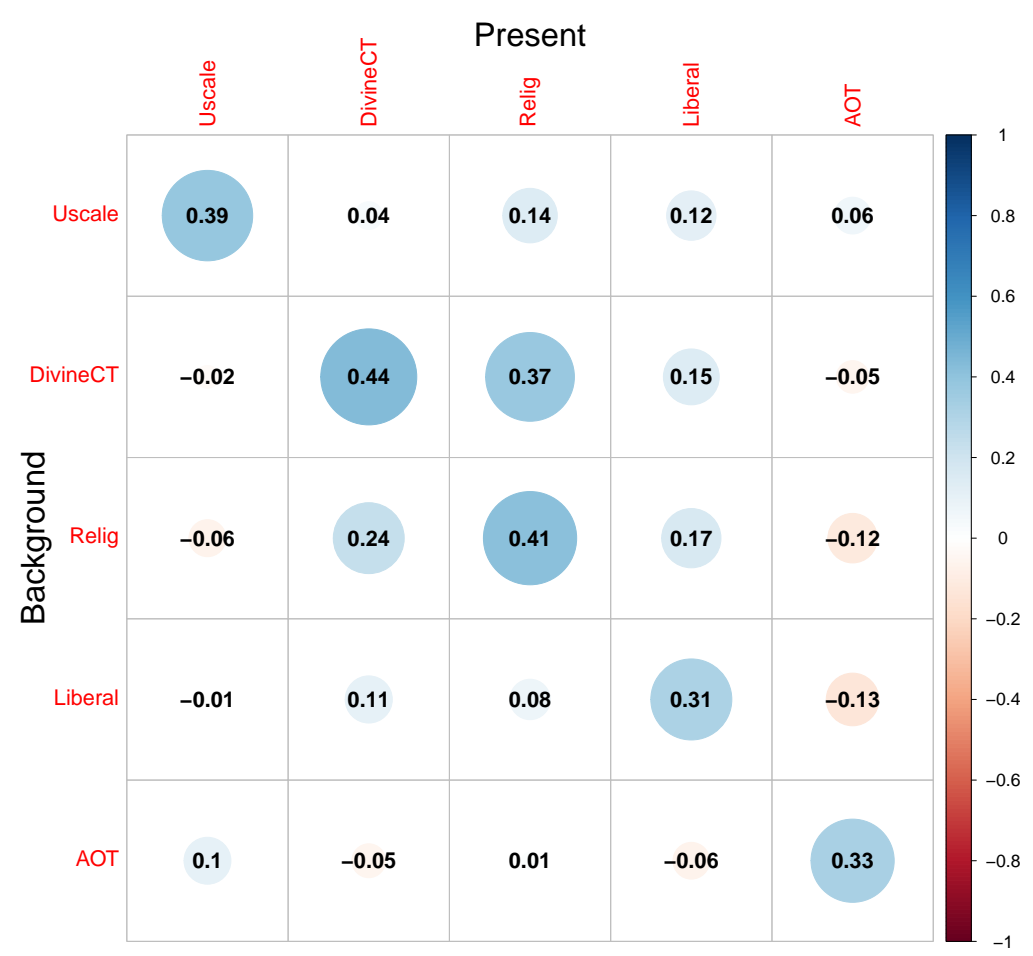

FIGURE 8: Correlations of Upbrining and mean responses of scales..

experiences, and thinking may also lead people to seek different sorts of people, education and experiences. We thus report the results of the Thought measure, but note that the main results are substantively the same with each of Others, Educ, and Exper.

Figures 9 shows the correlations of the subject-mean influence measures with each of the scales. Again, we see that Upbring influence has low but positive correlations with all scales, even though subjects thought that its effect was opposite to greater liberalism, hence opposite to the predominant direction of change, as shown in Figure 10.

By contrast, Figure 10 shows the correlations between the same influence measures and the change from Past to current. Here, consistent with the results in Figure 7, the influence of Upbring goes against the change to more liberal beliefs.

Figures 11 and 12 show the correlations by items illustrating the positive correlations with one's own thinking and the negative correlations with Upbring. In sum, subject thought that their change over time was influenced in a more liberal direction by their own thinking but in the opposite direction by their upbringing.

We could also whether AOT was particularly important in bringing about change from the past by looking at the correlation between the average of each scale for both times and change from past to present for each scale. Averaged AOT did not correlate substantially with any changes in other scale (highest was .11 for Liberal), and neither did any other scale, except for averaged Uscale, which correlated .35 with change in Relig only. Results for comparison of past with background were also mostly negative except that averaged DivineCT correlated .23 with change in Relig. In summary, no particular trait that we 


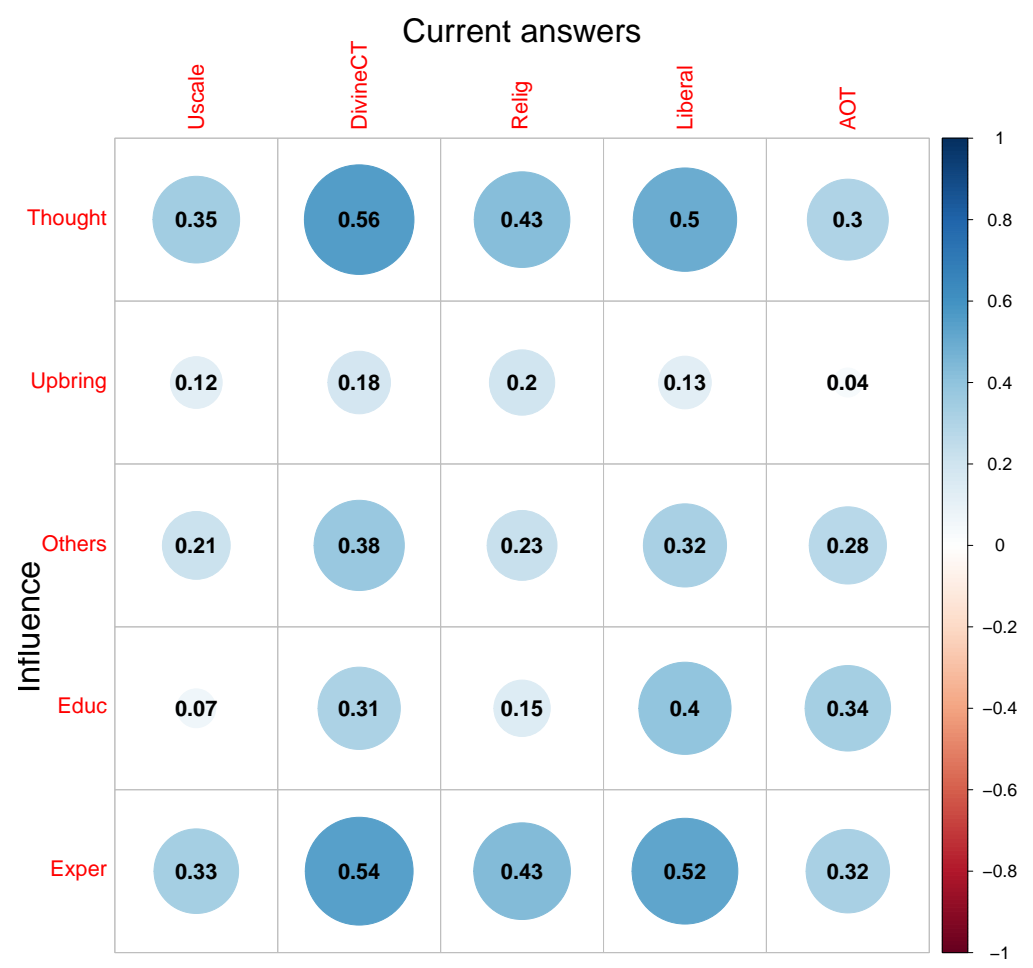

FIGURE 9: Correlations of influence measures (means for each subject) with current answers by scale.

assessed seemed to cause broad changes in the others. When subjects said that changes resulted from their own thought, they seem to have meant that they thought about each issue.

\section{Conclusion}

There is a positive manifold among measures of deontology, social conservatism, parochialism, religious "fundamentalism", and non-acceptance of AOT. This positive manifold may occur (as it does for cognitive abilities) for a variety of reasons. Some traits may affect others. AOT could lead to cosmopolitanism, rejection of moralistic values (personal values imposed on others), and utilitarianism. Utilitarianism can lead to cosmpolitanism. Belief in divine command theory can make people resist AOT.

Similar forces may work within cultures, and acculturation may affect individual thinking and beliefs. It is difficult to account for the full pattern of results without considering effects of culture. For example, Divine Command Theory does not seem like a view that people are likely to hold as a result of their own thinking, although it does seem to have been individually invented at least once by the writers of the Bible. Cultural beliefs and values may be maintained because they set up institutions to maintain themselves over generations (Cavalli-Sforza et al., 1982). 


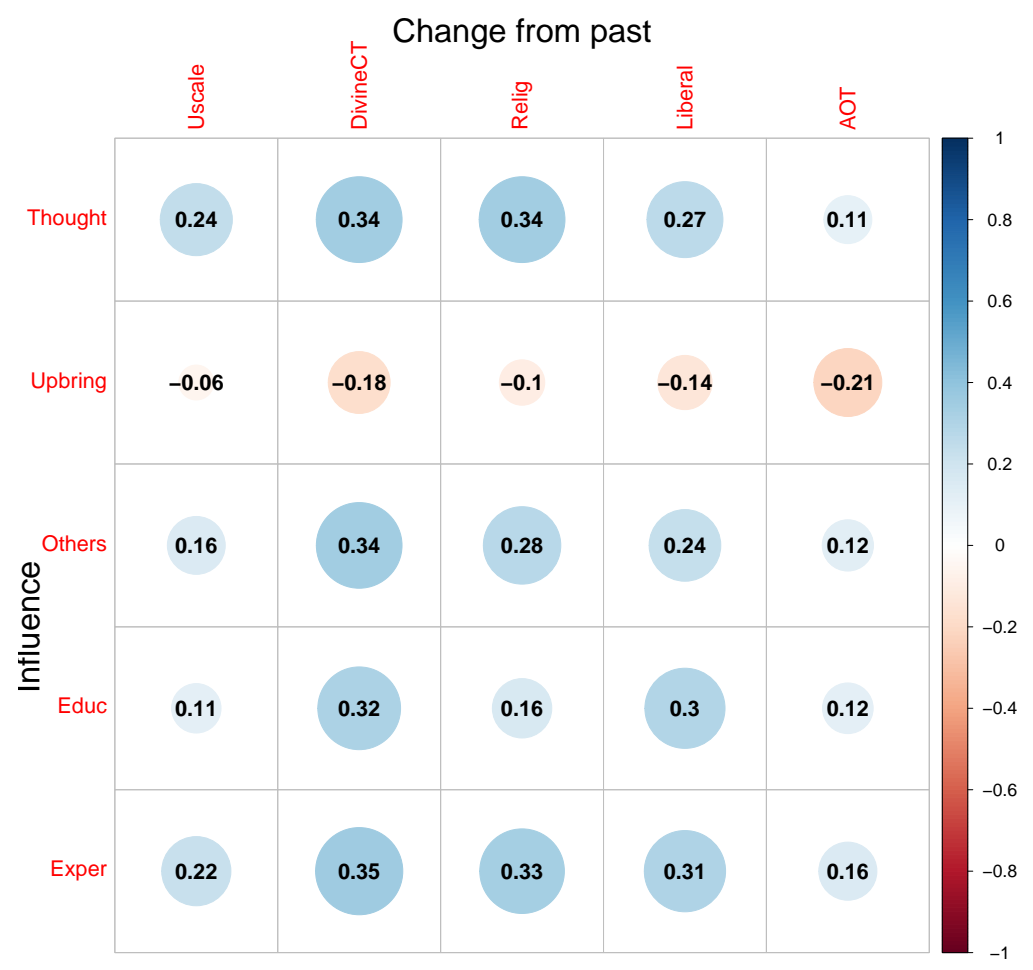

FIGURE 10: Correlations of influence measures (means for each subject) with change from past to current.

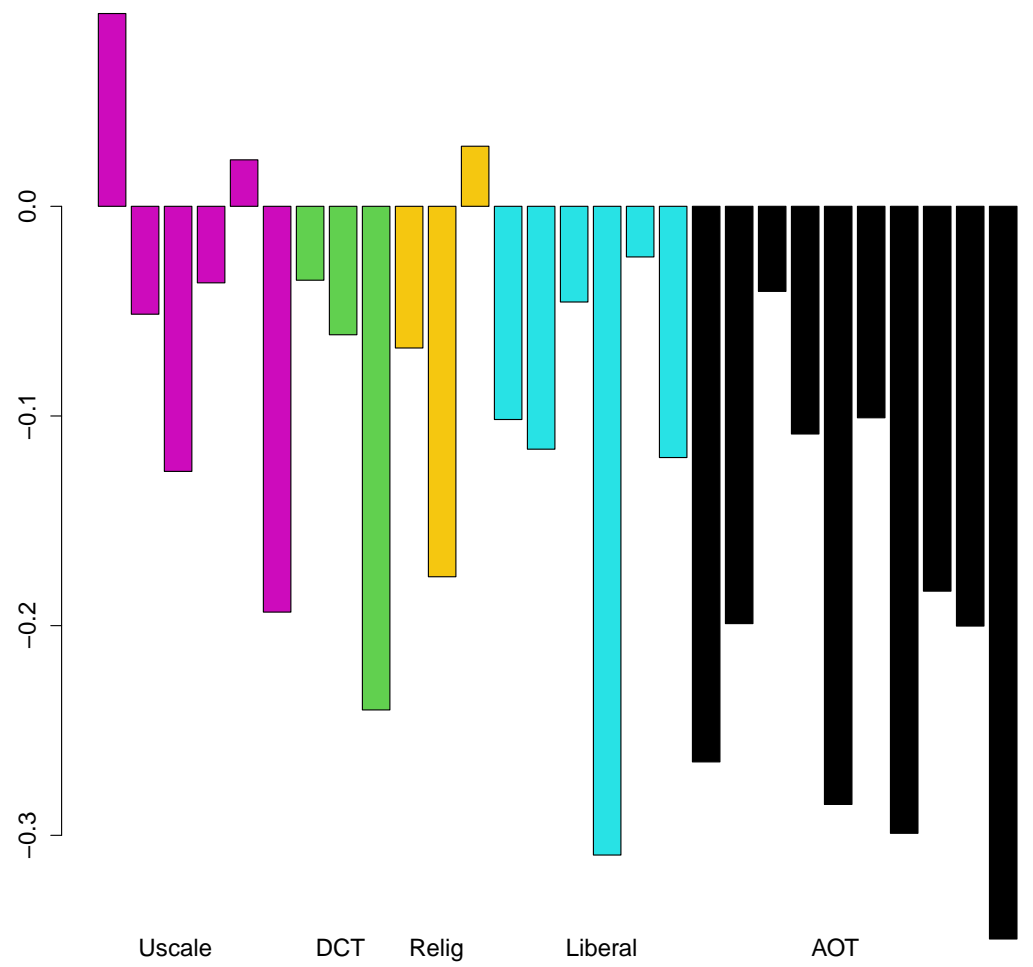

FIGURE 11: Correlations of Upbring influence items with change from past $(\mathrm{N}=130)$. 


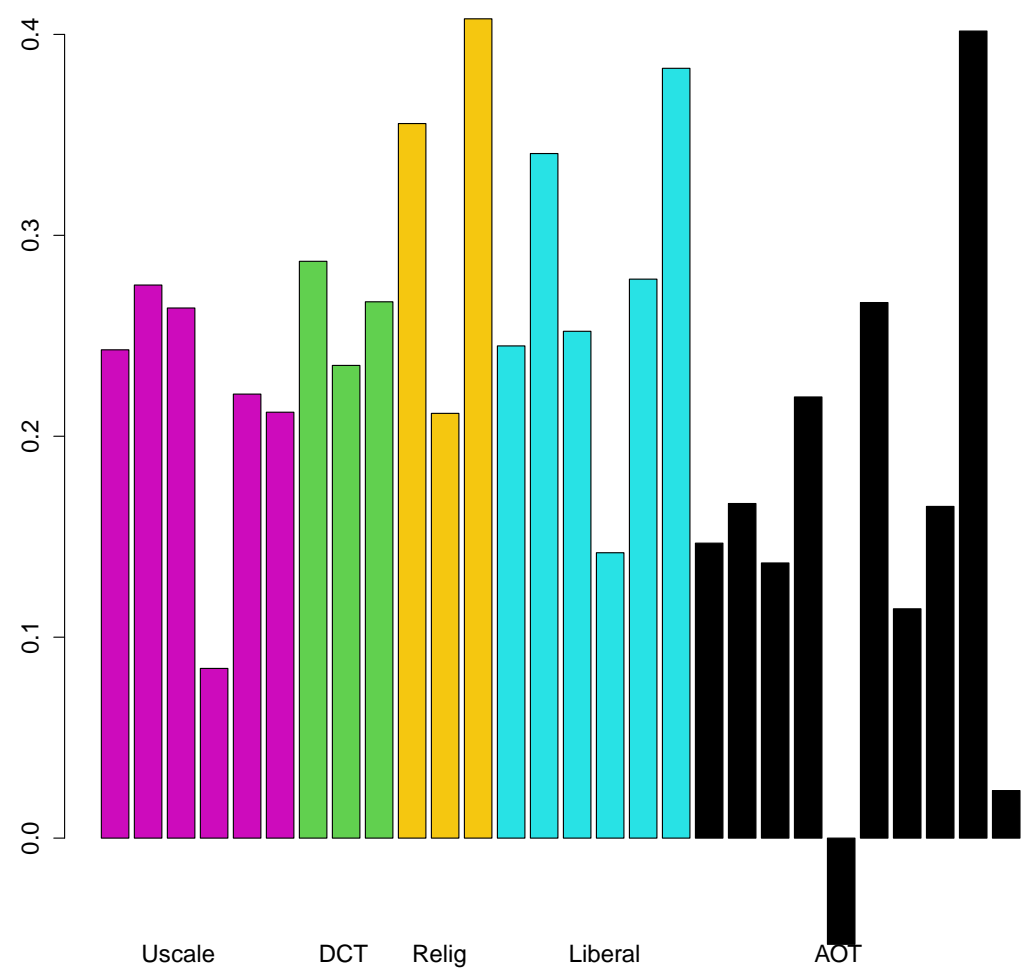

Figure 12: Correlations of Thought influence items with change from past $(\mathrm{N}=130)$.

Yet some people become more cognitively liberal over their lives. Some of this is the effect of "thought about it myself." Such thought seems to be affected by other influences aside from the sort of upbringing we asked about, such as teachers, friends, or experiences with strangers. But it does not seem to be simply the transmission of culture, as that would not explain the apparent movement toward cognitive liberalism.

Rather, it seems possible that AOT itself is something that people discover for themselves. The starting point may be the simple recognition that people make mistakes, and that one way to prevent such mistakes is to look for possible causes, including reasons why some conclusion of the moment might turn out to be wrong. People can of course learn to do this sort of search without recognizing what they are doing, but it should not be difficult to take the next step to a meta-cognitive principle, which then becomes an explicit standard. Thus, we have expressions in common language that arise from this sort of meta-cognition, e.g., "pig-headed", "narrow-minded", and "open-minded". The next step after this is the realization that overconfidence can shut down search prematurely: "It ain't what you don't know that gets you into trouble. It's what you know for sure that just ain't so." 8

AOT is important for politics. It would be nice if everyone adopted this sort of standard and used it as a basis of argument, in legislatures and their committees, in news sources, in public statements, as well as between individuals when they discuss politics, if they ever "discuss" it in this sense anymore. AOT is thus a moral virtue as well as a personal one.

${ }^{8}$ Attributed to Mark Twain but not found in any of his writings. 
For individuals, this standard can serve as a basis for evaluating sources. Much of what seems to be belief in partisan conspiracy theories may result from listening to sources who would not be trustworthy by the standards of AOT.

The concept of AOT has some advantages not shared by other concepts of cognitive style. It is more generally useful than measures based on the idea that more thinking is always better. It is not better when it serves simply to bolster an initial judgment by looking only for supporting reasons. The standards of AOT are consistent with the argument that it is sometimes better not to make judgments on one's own without help from trustworthy sources, who may reduce the amount of thinking that an individual needs to do in order to reach valid conclusions.

Politically, AOT is at least on its face more neutral than some other trait measures, such as measures of dogmatism or authoritarianism, which often contain what amounts to disputed political content. Such content may result from good or bad thinking, but it is not descriptive of thinking itself.

Despite the apparent political neutrality of AOT, it is still part of the "culture wars" playing out around the world. Explicit teaching of AOT in schools would surely be opposed by those with strong traditional values, who could see AOT as a back door to challenging values that ought to be accepted without question. Those who favor AOT should thus be prepared for battle in these wars.

\section{References}

Ackerman, R., \& Thompson, V. A. (2017). Meta-reasoning: Monitoring and control of thinking and reasoning. Trends in Cognitive Sciences, 21(8), 607-617.

Bago, B., \& De Neys, W. (2017). Fast logic?: Examining the time course assumption of dual process theory. Cognition, 158, 90-109.

Baron, J. (1985). Rationality and intelligence. New York: Cambridge University Press.

Baron, J. (1991). Beliefs about thinking. In J. F. Voss, D. N. Perkins, \& J. W. Segal (Eds.), Informal reasoning and education, pp. 169-186. Hillsdale, NJ: Erlbaum.

Baron, J. (1995). Myside bias in thinking about abortion. Thinking and Reasoning, 1, 221-235.

Baron, J. (2009). Belief overkill in political judgments. (Special issue on Psychological Approaches to Argumentation and Reasoning, edited by L. Rips). Informal Logic, 29, 368-378.

Baron, J. (2017). Comment on Kahan and Corbin: Can polarization increase with actively open-minded thinking? Research and Politics, 4(1).

Baron, J. (2019). Actively open-minded thinking in politics. Cognition, 188, 8-18.

Baron, J., Badgio, P. C., \& Ritov, Y. (1991). Departures from optimal stopping in an anagram task. Journal of Mathematical Psychology, 35(1), 41-63.

Baron, J., \& High, D. II. (2019). People who endorse AOT are sensitive to cues indicating 
AOT of sources Poster presented at the Society for Judgment and Decision Making, Montreal, Nov. 15-18. http://www.sjdm.org/presentations/2019-Poster-Baron-Jonathan-endorse-AOT-cues. pdf.

Baron, J., Scott, S., Fincher, K., \& Metz, S. E. (2015). Why does the Cognitive Reflection Test (sometimes) predict utilitarian moral judgment (and other things)? Journal of Applied Research in Memory and Cognition, 4(3), 265-284.

Bronstein, M. V., Pennycook, G., Bear, A., Rand, D. G., \& Cannon, T. D. (2019). Belief in fake news is associated with delusionality, dogmatism, religious fundamentalism, and reduced analytic thinking. Journal of Applied Research in Memory and Cognition, 8(1), $108-117$.

Brownstein, A. (2003). Biased predecision processing. Psychological Bulletin, 129, 545568.

Bryan, W. L., \& Harter, N. (1899). Studies on the telegraphic language: The acquisition of a hierarchy of habits. Psychological Review, 6, 345-375.

Cavalli-Sforza, L. L., Feldman, M. W., Chen, K. H., \& Dornbusch, S. M. (1982). Theory and observation in cultural transmission. Science, 218(4567), 19-27.

DeKay, M. L., Patino-Echeverri, D., \& Fischbeck, P. S. (2009). Distortion of probability and outcome information in risky decisions. Organizational Behavior and Human Decision Processes, 109(1), 79-92.

Deppe, K. D., Gonzalez, F. J., Neiman, J. L., Jacobs, C., Pahlke, J., Smith, K. B., \& Hibbing, J. R. (2015). Reflective liberals and intuitive conservatives: A look at the Cognitive Reflection Test and ideology. Judgment and Decision Making, 10, 314-331.

Evans, J. S. B., \& Stanovich, K. E. (2013). Dual-process theories of higher cognition: Advancing the debate. Perspectives on psychological science, 8(3), 223-241.

Fieldhouse, E., J. Green., G. Evans., H. Schmitt, C. van der Eijk, J. Mellon \& C. Prosser (2018) British Election Study Internet Panel Wave 14. https://www.britishelectionstudy. com/data-object/wave-14-of-the-2014-2018-british-election-study-internet-panel/

Flavell, J. H. (1979). Metacognition and cognitive monitoring: A new area of cognitivedevelopmental inquiry. American psychologist, 34(10), 906-911.

Frederick, S. (2005). Cognitive reflection and decision making. Journal of Economic Perspectives, 19, 24-42.

Fuhrer, J., \& Cova, F. (2020). "Quick and dirty": Intuitive cognitive style predicts trust in Didier Raoult and his hydroxychloroquine-based treatment against COVID-19. Judgment and Decision Making, 15, 889-908.

Galotti, K. M., Baron, J., \& Sabini, J. (1986). individual differences in syllogistic reasoning: Deduction rules or mental models. Journal of Experimental Psychology: General, 115, $16-25$.

Hallpike, C. R. (2004). The evolution of moral understanding. London: Prometheus Research Group.

Haran, U., Ritov, I., \& Mellers, B. A. (2013). The role of actively open-minded thinking in information acquisition, accuracy, and calibration. Judgment and Decision Making, 8, 
$188-201$.

Hart, W., Albarracín, D., Eagly, A. H., Brechan, I., Lindberg, M. J., \& Merrill. L. (2009). Feeling validated versus being correct: A meta-analysis of selective exposure to information. Psychological Bulletin, 135, 555-588.

Jern, A., Chang, K. K., \& Kemp. C. (2014). Belief is not always irrational. Psychological Review, 121, 206-224.

Jervis, R. (1976). Perception and misperception in international politics. Princeton: Princeton University Press.

Kagan, J., Rosman, B. L., Day, D., Albert, J., \& Phillips, W. (1964). Information processing in the child: Significance of analytic and reflective attitudes. Psychological Monographs, 78 (1, Whole No. 578).

Kahane, G., Everett, J. A. C., Earp, B. D., Caviola, L., Faber, N. S., Crockett, M. J., \& Savulescu, J. (2018). Beyond sacrificial harm: A two-dimensional model of utilitarian psychology. Psychological Review, 125(2), 131-164.

Kahneman, D. (2011). Thinking, fast and slow. New York: Farrar, Strauss and Giroux.

Kohlberg, L. (1969). Stage and sequence: The cognitive developmental approach to socialization. In D. Goslin (Ed.), Handbook of socialization theory and research (pp. 347-480). New York: Rand McNally \& Company.

Kuhn, D. (1989). Children and adults as intuitive scientists.</a > Psychological Review, 96, 674-689.

Lee, M. D., \& Courey, K. A. (2021). Modeling optimal stopping in changing environments: A case study in mate selection. Computational Brain \& Behavior, 4(1), 1-17.

Lord, C. G., Ross, L., \& Lepper, M. R. (1979). Biased assimilation and attitude polarization: The effects of prior theories on subsequently considered evidence. Journal of Personality and Social Psychology, 37, 2098-2109.

Marcia, J. E. (1980). Identity in adolescence. In J. Adelson (Ed.), Handbook of adolescent psychology, 9(11), 159-187.

Messer, S. B. (1976). Reflection-impulsivity: A review. Psychological Bulletin, 83(6), 1026.

Meszaros, J. R., Asch, D. A., Baron, J., Hershey, J. C., Kunreuther, H., \& SchwartzBuzaglo, J. (1996). Cognitive processes and the decisions of some parents to forego pertussis vaccination for their children. Journal of Clinical Epidemiology, 49, 697-703.

Metz, S. E., Baelen, R. N., \& Yu, A. (2020) Actively open-minded thinking in American adolescents. Review of Education, 8, 768-799.

Perry, W. G., Jr. (1971). Forms of intellectual and ethical development in the college years: A scheme. New York: Holt, Rinehart \& Winston.

Piazza, J., \& Landy, J. F. (2013). "Lean not on your own understanding": Belief that morality is founded on divine authority and non-utilitarian moral judgments. Judgment and Decision Making, 8, 639-661

Pennycook, G., Cheyne, J. A., Barr, N., Koehler, D. J., \& Fugelsang, J. A. (2014). Cognitive style and religiosity: The role of conflict detection. Memory \& Cognition, 42(1), 1-10. 
Pennycook, G., Cheyne, J. A., Koehler, D. J., \& Fugelsang, J. A. (2020). On the belief that beliefs should change according to evidence: Implications for conspiratorial, moral, paranormal, political, religious, and science beliefs. Judgment and Decision Making, 15, 476-498.

Ratcliff, R., Thompson, C. A., \& McKoon, G. (2015). Modeling individual differences in response time and accuracy in numeracy. Cognition, 137, 115-136.

Revelle, W. (2021). psych: Procedures for Psychological, Psychometric, and Personality Research. R package version 2.1.9. https://CRAN.R-project.org/package=psych

Ross, R. M., Rand, D. G., \& Pennycook, G. (2021). Beyond "fake news": Analytic thinking and the detection of false and hyperpartisan news headlines. Judgment and Decision Making, 16, 484-504.

Russo, J. E., Carlson, K. A., \& Meloy, M. G. (2006). Choosing an inferior alternative. Psychological Science, 17(10), 899-904

Shiffrin, R. M., \& Schneider, W. (1977). Controlled and automatic human information processing: II. Perceptual learning, automatic attending and a general theory. Psychological Review, 84(2), 127-190.

Schneider, W., \& Shiffrin, R. M. (1977). Controlled and automatic human information processing: I. Detection, search, and attention. Psychological Review, 84(1), 1-66.

Sinclair, A. H., Stanley, M. L., \& Seli, P. (2020). Closed-minded cognition: Rightwing authoritarianism is negatively related to belief updating following prediction error. Psychonomic Bulletin \& review, 27(6), 1348-1361. https://osf.io/a85rq

Sirota, M., \& Juanchich, M. (2018). Effect of response format on cognitive reflection: Validating a two-and four-option multiple choice question version of the Cognitive Reflection Test. Behavior research methods, 50(6), 2511-2522.

Stanovich, K. E., \& West, R. F. (1997). Reasoning independently of prior belief and individual differences in actively open-minded thinking. Journal of Educational Psychology, 89(2), 342-357.

Stroop, J. R. (1935). Studies of interference in serial verbal reactions. Journal of experimental psychology, 18(6), 643-662.

Svedholm-Häkkinen, A. M., \& Lindeman, M. (2017). Actively open-minded thinking: Development of a shortened scale and disentangling attitudes toward knowledge and people. Thinking and Reasoning, 24(1), 21-40.

Thompson, V. A., Prowse Turner, J. A. \& Pennycook, G. (2011). Intuition, reason, and metacognition. Cognitive Psychology, 63(3), 107-140.

Toplak, M. E., West, R. F., \& Stanovich, K. E. (2014). Rational thinking and cognitive sophistication: Development, cognitive abilities, and thinking dispositions. Developmental Psychology, 50(4), 1037-1048.

Wason, P. C., \& Evans, J. St. B. T. (1975). Dual processes in reasoning? Cognition, 3, $141-154$.

Yilmaz, O., \& Saribay, S. A. (2017). The relationship between cognitive style and political orientation depends on the measures used. Judgment and Decision Making, 12, 140-147. 